\title{
The Effect of Leader Knowledge Hiding on Employee Voice Behavior-The Role of Leader-Member Exchange and Knowledge Distance
}

\author{
Chen Chen \\ School of Management, Jinan University, Guangdong, China \\ Email: doublingchen@126.com
}

How to cite this paper: Chen, C. (2020). The Effect of Leader Knowledge Hiding on Employee Voice Behavior-The Role of Leader-Member Exchange and Knowledge Distance. Open Journal of Social Sciences, 8, 69-95.

https://doi.org/10.4236/jss.2020.84006

Received: March 5, 2020

Accepted: April 6, 2020

Published: April 9, 2020

Copyright (อ 2020 by author(s) and Scientific Research Publishing Inc. This work is licensed under the Creative Commons Attribution International License (CC BY 4.0).

http://creativecommons.org/licenses/by/4.0/

(c) (i) Open Access

\begin{abstract}
Knowledge hiding behavior is common in the organization, which hinders the cooperation among employees and affects the transmission and development of new knowledge and new ideas. Therefore, based on the social exchange theory, this study takes 441 employees as the research object. The research results are as follows: 1) Perceived leader evasive hiding and perceived leader playing dumb had a negative effect on employee voice behavior. Perceived leader rationalized hiding has no significant influence on employee voice behavior. 2) LMX completely mediated the relationship between perceived leaders' evasive hiding, playing dumb and voice behavior. 3) The moderating effect of knowledge distance on the influence of perceived leader knowledge hiding on LMX is significant. The greater the knowledge distance, the stronger the negative effect of perceived leadership knowledge hiding and LMX. This study suggests that managers should pay more attention to the possible negative impact of leader knowledge hiding and knowledge distance on employees' voice behaviors, and to increase knowledge exchange with employees, to establish reasonable talent configuration in teams or organizations, as well as create a harmonious interpersonal atmosphere for employees' voicing.
\end{abstract}

\section{Keywords}

Perceived Leader Knowledge Hiding, Employee Voice Behavior,

Leader-Member Exchange, Knowledge Distance, Social Exchange Theory

\section{Introduction}

In the era of knowledge economy, the competitive advantage of organizations is 
more and more dependent on knowledge management and organizational learning (He \& Jiang, 2014). Successful knowledge management systems depend on employee behavior (Riege, 2005). For any form of organization, knowledge is not enough to make an organization successful, effective knowledge management is the key element of organizational development. The lack of effective knowledge management leads to the instability and even crisis of enterprises from time to time, such as the repeated occurrence of quality defects of some enterprises, the serious blow caused by the loss of backbone of some enterprises, some enterprises are stuck in their ways, failed to keep up with the technological progress and are eliminated and so on. Knowledge sharing, as an important part of knowledge management, has always been a problem. Employees are unwilling to share their knowledge, which forms an "island of knowledge" in the organization. The research results show that there are still quite a few employees unwilling to share knowledge, or even deliberately conceal knowledge requests from other employees, namely knowledge hiding (Connelly, Zweig, Webster, \& Trougakos, 2012). In recent years, scholars have showed great interest to knowledge hiding (Černe, Hernaus, Dysvik, \& Škerlavaj, 2017; Černe, Nerstad, Dysvik, \& Škerlavaj, 2014; Kumar Jha, \& Varkkey, 2018; Serenko \& Bontis, 2016).

The current research on the phenomenon of knowledge hiding on the one hand, mainly focused on the individual knowledge hiding micro-level discussion, but knowledge hiding not only between employees, several studies show that like employees produce emotional attachment to the organization, they may give their attention on the focus of the organization, such as leader (Becker, 1992; Clugston, Howell, \& Dorfman, 2000; Gregersen, 1993; Stinglhamber, Bentein, \& Vandenberghe, 2002), leadership and subordinate's interaction are also the important channel which the flow of information and knowledge hiding of management is widespread (Černe et al., 2014; Connelly \& Zweig, 2015; Connelly et al., 2012; Peng, 2013), Therefore, the double-effect mechanism of knowledge hiding between leaders and ordinary employees needs further exploration and analysis (Arain, Bhatti, Ashraf, \& Fang, 2018; Butt \& Ahmad, 2019; Fong \& Slotta, 2018). On the other hand, there's a lot of research on antecedent variables of knowledge hiding, previous research has shown that employees between knowledge hidden hazards, such as creative destruction (Černe et al., 2014; Černe et al., 2017), inhibit the spread of new knowledge and development (Černe et al., 2014), and increase turnover intention (Connelly et al., 2012), etc. However, in order to succeed in a rapidly changing market, organizations need to obtain information from different channels to maintain flexibility and innovation. In addition to the wisdom from management, another is through employee voice behavior. The ideas expressed by employees through voice behavior belong to the information category in essence. There are numerous examples of employees contributing their intelligence and wisdom to promote the progress of the organization through voice behavior, which is what enterprises want to see. However, in reality, employees often have ideas but are unwilling to express them, which may be because they are afraid of damaging interpersonal relations 
due to the expression of inconsistent opinions, or because they lack effective channels for voice behavior.

Leadership is one of the important factors of advice behavior in group situations, subordinates voice behavior often show the share their ideas with the superior, the superior is the advice of object (Avolio, 2007; Avolio et al., 2004; Detert \& Treviño, 2010). Through the literature found that most of the scholars in the study of leadership and employee voice behavior, from the perspective of leadership styles, more differences between the study of different leadership styles and staff voice (Liborius, 2014; Nguyen, Chen, \& De Cremer, 2017; Zhu \& Akhtar, 2019). The breakthrough point of this study is the knowledge hiding behavior of leaders. Different from previous studies on individual's own knowledge hiding, this paper explains the influence on employees' voice behavior motivation from the perspective of perception, and distinguishes knowledge hiding from different dimensions, so as to better reveal the mechanism of perceived leader knowledge hiding on voice behavior.

Therefore, on the basis of previous studies and based on the social exchange theory, this paper investigates the internal mechanism of the perceived knowledge hiding of leaders on employees and the influence of employees on leadership information sharing, namely voice behavior, and probes into the mediating role of leader member exchange, so as to expand the research on the effect of knowledge hiding. At the same time, knowledge distance is introduced as a representative factor of the difference between the knowledge level of leaders and employees, to explore the moderating effect of different knowledge distance levels, and further explain and clarify the situational factors of the effect of leadership knowledge hiding, so as to provide practical guidance for promoting the voice behavior of employees in the organization.

\section{Theory and Hypothesis Development}

\subsection{Knowledge Hiding}

Connelly et al. (2012) first explicitly put forward the concept of knowledge hiding. He defines knowledge hiding as the behavior that an individual in an organization intentionally conceals or deliberately conceals knowledge requests from colleagues (including superiors, peers and subordinates). The knowledge here mainly includes information, perspectives, and professional expertise related to the performance of organizational members in completing tasks, etc. (Connelly et al., 2012). The situation concerned by this definition refers to the result of an individual's subjective choice tendency that the respondent deliberately adopts different strategies to retain or hide knowledge under the premise that he/she knows the knowledge asked when he/she is asked for help from colleagues about a specific knowledge. In fact, there are multiple reasons to argue that supervisors do hide knowledge from their supervisees. Leaders' psychological ownership of their knowledge and their fears of losing power, being taken advantage of, and being exploited by their supervisees can lead to leader know- 
ledge hiding (Arain, Bhatti, Ashraf, \& Fang, 2018). Connelly et al. further explained the connotation of knowledge hiding, believing that it mainly includes three aspects: evasive hiding, pretending to be stupid and reasonable hiding.

1) Evasive hiding: when in the face of questions from a colleague, hidden information provided to the requestor is not correct, or promised to help, but as far as possible delay, has no intention to really help. For example, in the most common situation in the work scene, when a colleague asks for help for knowledge, the person being asked for help may say "yes, but I will be busy, I will have time to tell you later", but actually there is no intention to provide help later. Or in another case, providing incorrect information about the request, which involves some deception.

2) Playing dumb: when confronted with a question from a colleague, the person being asked pretends not to understand the question and is unwilling to help. The most common example is when a colleague asks for knowledge assistance, pretending "I don't know" or "I don't know" to deny it directly, even though they do know it, which also involves deception.

3) Rationalized hiding: when confronted with a question from a colleague, the concealer fails to provide the knowledge or information the requester wants because the third party is unwilling to disclose the knowledge or information. For example, a colleague asked an employee if he could have a copy of a report, and the employee replied that the information was confidential and he could not give it to anyone. This kind of behavior, to some extent, does not necessarily involve deception.

To sum up, three different types of hiding strategies have different harmful effects on the organization. Rationalized hiding behaviors do not necessarily have a deceptive effect, so it will not have a negative impact on the interpersonal relationship between colleagues, and to some extent have a positive impact on the protection of confidential knowledge within the organization. However, the two kinds of hiding behaviors, such as evasive hiding and playing dumb, involve deception, which will not only seriously harm the interpersonal trust relationship between colleagues, but also lead to the negative reciprocity psychology of knowledge seekers in the long run. Second, when they become the party to be asked for help, they will take malicious revenge instead of giving help, resulting in a vicious circle of reciprocity, which seriously affects the atmosphere of knowledge sharing and even knowledge innovation.

\subsection{Perceived Leader Knowledge Hiding and Employee Voice Behavior}

A large number of studies have shown that leadership is an important factor influencing voice behavior. In organizational situations, subordinates' voice behavior is often manifested as sharing their own ideas with their superiors, who are the objects of voice behavior, so superiors play a crucial role in the voice behavior process (Becker, 1992; Clugston, Howell, \& Dorfman, 2000; Gregersen, 1993; Stinglhamber, Bentein, \& Vandenberghe, 2002; Detert \& Burris, 2007). 
The study found that employees are reluctant to voice behavior for two most common reasons. First, they are afraid of negative results due to voice behavior; the other is that they believe that no change will be caused even if a proposal is made (Morrison \& Milliken, 2000). Therefore, there are two important conditions in the mechanism of cognitive occurrence before individuals make voice behavior decisions (Detert \& Edmondson, 2006; Detert \& Burris, 2007): first, voice behavior occurs at the individual considered to be security and it is worth, effective judgment based on this cognition; second, there is an expected evaluation process of voice behavior results before individuals make voice behavior, that is, they consciously make an expected evaluation of the costs and expected benefits of voice behavior. If voice behavior can be adopted by leaders and have an impact on organizational performance, employees will receive rewards and positive feedback. On the contrary, if voice behavior is misinterpreted by leaders, it will bring certain risks to employees (Lee, Choi, Youn, \& Chun, 2017). Voice behavior challenges as a risky behavior, have self initiated, proactive, long term oriented, and need to overcome the difficulties of the psychological quality and ability, its behavior is built on a high level of cognitive state, whether the accuracy of the information processing, depth and cognitive cost at a high level of processing (Chiaburu \& Harrison, 2008), the final decision is based on the rational behavior analysis, evaluation and judgment, the expectations of the result is positive.

Social exchange theory (Blau, 1964) has been applied to most researches on voice behavior, and the norm for reciprocity is used for interpretation (Shore et al. 2009). The premise of this theoretical perspective is that employees' participation in voice behavior is aimed at managing the quality of their social exchange relationship with others, and is more people-oriented (Ng \& Feldman, 2012). Social exchange theory holds that interpersonal relationships evolve over time and how they develop depends on the exchange rules among different stakeholders. Reciprocity norm, as a common law of social exchange, has received the most attention. When the individual receives the benefits provided by others, he will correspondingly provide the benefit providers with the necessary benefits in return. Over time, this reciprocity norm will lead the social exchange between the two parties to a state of trust and positive emotional involvement, that is, both parties establish a high-quality social exchange relationship (Settoon, Bennett, \& Liden, 1996). Researchers think that if employees think of themselves and the relationship between the organization is mutual trust, respect, and a satisfying, so employees in order to return in the mutual exchange organization, often beyond their own responsibilities efforts, especially when the further development of some potential problems affect the organization, employees will be more actively involved in the voice behavior (Ng \& Feldman, 2012).

Leaders' behavior can either encourage employees to ask questions or take risks, or it can lead to submissive silence (Milliken, Morrison, \& Hewlin, 2003). Employees perceive that the leaders give positive responses and help to their knowledge requests, which facilitates the effective flow of information between 
the superior and the subordinate, so that employees can feel the leaders' help and support. But for this kind of reward for good behavior with people, and strive to maintain the friendly relationship between leadership and demand, employees will work harder to solve problems encountered in work, actively put forward new opinions and ideas, try to be creative and effective way to improve work processes, in this kind of direct or indirect way to help a leader to finish the work better.

Similarly, negative reciprocity also exists in organizations. When the leader has a lot of negative relationships in the team, the message will be sent to the employees: the leader is not receptive to the new suggestions that will challenge the status quo, and he is defensive to the voice behavior of the subordinates. These clues significantly reduce employees' perception of leadership openness, leading them to believe that leaders take advantage of power and position to punish employees, resulting in employees' unwillingness to conduct voice behavior (Detert \& Burris, 2007; Venkataramani et al., 2016). When individuals perceive negative behaviors or improper behaviors, such as deliberately hiding information in evasive hiding and playing dumb, a state of distrust will be formed (Grovier, 1994). Distrust of a person will lead to the same response (Gouldner, 1960). If employees perceive that the leaders turn a blind eye to their knowledge requests, repeatedly shirking (evasive hiding) or pretending to be stupid and not telling themselves (playing dumb), it will make it difficult for employees to get close to the leaders, and the social distance between the two is widening, and they cannot get important information in time, employees will judge that voice behavior is risky and lose the motivation of voice behavior.

But the rationalized hiding given the staff information about not inform responses, and does not involve cheating, and to a certain extent, has a positive influence on confidential knowledge within the organization to protect (Connelly \& Zweig, 2015), employees can understand leadership knowledge hidden reasons, believe that leadership is the ability to communicate and get feedback, voice behavior can increase instead. Thus, we hypothesize the following relationship.

H1a: Perceived leader evasive hiding is negatively associated with employee voice behavior.

$\mathrm{H} 1 \mathrm{~b}$ : Perceived leader playing dumb is negatively associated with employee voice behavior.

H1c: Perceived leader rationalized hiding is positively associated with employee voice behavior.

\subsection{The Mediation of LMX between Perceived Leader Knowledge Hiding and Voice Behavior}

Knowledge hiding is a behavior that occurs in the interaction between requester and concealer in the workplace. It is reasonable to believe that how the concealer responds to the requester directly affects the quality of interpersonal interaction. As Goulder (1960) pointed out, the return of adverse results to those who engage 
in negative behaviors can ensure the stability of the social system and help prevent the spread of negative behaviors. According to the reciprocity principle of social exchange theory, the leadership of the request to the knowledge of all employees, provides employees with more exchange of resources, so as to make them feel the care and trust from the supervisor, make employees have led to yourself, to be able to establish good social exchange relationship with leadership (Avolio, 2007), and generate returns the pressure, strong sense of obligation to return inspire employees strongly gratitude (Eisenberger et al., 2001), and further make employees with positive work attitude and behavior.

LMX theory points out that leaders usually develop different exchange relationships with each employee, which cover a range of one-way, low-quality exchange relationships from top down to two-way, high-quality exchange relationships with reciprocal influence. In a low-quality exchange relationship, the leader and the employee are limited to the formal authority relationship of top to bottom, and the employee usually only does some work within the role. In a high-quality exchange relationship, leaders and employees will transcend the formal authority boundaries between the upper and lower levels to develop a relationship of mutual trust, support and reciprocity, and subordinates are often willing to show more extra-role behaviors (Graen, Dansereau \& Minami, 1972; Dansereau, Graen, \& Haga, 1975; Liden \& Graen, 1980; Dienesch \& Liden, 1986; Graen \& Scandura, 1987; Graen \& Uhl-Bien, 1995; Le Blanc \& González-Romá, 2012), such as voice. In high-quality LMX, there is a high sense of mutual trust between leaders and employees, and leaders often have high-level requirements on employees. They expect their subordinates to put collective interests before individual short-term interests (Gerstner \& Day, 1997). At the same time, the close relationship with the leader and the benefits it brings can make employees have a sense of reciprocal obligation, which is one of the key incentives to motivate employees' positive voice behavior (Milliken, Morrison, \& Hewlin, 2003). Both evasive hiding and playing dumb involve deception, lying and non-cooperation (Pan et al., 2016). In addition, Connelly and Zweig (2015) found that deception involved in evasive hiding and playing dumb can cause harmful threats to interpersonal relationships, thus damaging organizational innovation and profitability. Therefore, evasive hiding and playing dumb of perceived leaders will damage the quality of exchange between leaders and employees. Employees can't feel the attention from leaders, so the distance between employees and their leaders is getting further and further. Employees with low quality LMX, on the other hand, take up less leadership time, are less likely to receive rewards, and are more likely to engage in behaviors that meet the minimum hiring requirements. Therefore, some knowledge hiding behaviors of leaders will lower LMX, thus reducing voice behavior of employees.

However, unlike evasive hiding and playing dumb, rationalized hiding is not always negative and may have positive results (Pan et al., 2016), for example does not involve the use of deception, designed to protect the interests of a third party 
or to avoid harm other people's feelings (Černe et al., 2014). In this case, employees may feel that the leaders' rational hiding behavior conforms to organizational norms and does not involve hurting their feelings (Pan et al., 2016). As a result, they may improve LMX. Based on the perspective of social exchange, empirical research shows that LMX significantly positively affects employee voice behavior (Detert \& Burris, 2007; Van Dyne et al., 2008). Together, we hypothesize that:

H2a: LMX mediates the negative association between perceived leader evasive hiding and employee voice behavior.

H2b: LMX mediates the negative association between perceived leader playing dumb and employee voice behavior.

H2c: LMX mediates the positive association between perceived leader rationalized hiding and employee voice behavior.

\subsection{The Moderating Role of Knowledge Distance}

Knowledge distance refers to the difference or similarity of knowledge level or knowledge content between individuals, which is reflected in the knowledge stock, knowledge level and knowledge communication between individuals (Cummings \& Teng, 2003). Existing research on intellectual potential, points out that in general, due to previous experience, ability, and the differences of social status, etc in the department, individuals perceive their relative knowledge potential in longitudinal relationships with superiors, the resulting differences between employees and leadership knowledge distance, extent of the impact of their behavior is also different (Halliday, 2005). An individual's perception of the situation affects individual behavior, and an excessive knowledge distance will weaken the effective reuse of others' knowledge and inhibit individual innovation (Hamel, 1991).

According to social exchange theory, the two parties in an exchange relationship will depend on each other to determine their relative power. Power comes from one party having the resources needed by the other. In a relationship, such interdependence will have the effect of influencing the behavior of "the more dependent party" (Emerson, 1962). So the exchange activity shows the power difference, which will be balanced over time. Both Homans and Blau believe that it is important for each party to feel the reciprocity of the exchange in carrying out some kind of exchange, so that in all social exchanges there is a mutual expectation that the exchange will be reciprocal. In the context of social exchange between employees and leaders, employees are relatively dependent on leaders, so leaders have relative power.

In the vertical interpersonal relationship formed with the direct leader, the increase of knowledge distance will increase the cognitive distance of both sides, which is not conducive to the formation of tacit relationship between the superior and the subordinate (Bergendahl \& Magnusson, 2015). Voice is full of risk and complexity, this means that for the individual recommendations need to pay a certain cost, due to the limited individual knowledge absorptive capacity and 
has the nature of risk aversion (Detert \& Burris, 2007), if it is difficult for employees to get material and spiritual support from superiors for voice behavior, the risk and complexity of voice behavior will increase. The increased risk of this mean for the individuals recommendations need to pay the cost of increased, due to the limited individual knowledge absorptive capacity and has the nature of risk aversion, advice behavior will be reduced. Tangirala and Ramanujam (2012) believe that perceived leadership position of employees moderates the positive relationship between the managers' consultation and employees' perceived influence. When employees believe that leaders have a high status in the organization, managers' consultation can promote employees' perceived influence. In addition to the formal leadership authority, the informal team position of the leader in the organization is also very important, which can help the leader to obtain and mobilize the organizational resources and utilize the collective support to implement the suggestions (Venkataramani et al., 2016). Due to the difference of status, employees are often unwilling to conduct voice behavior that challenges the status quo of the organization.

When the knowledge distance between staff and leadership is high, leadership both in social status and knowledge reserves in a dominant position, led by knowledge hiding and high knowledge distance makes difficult to achieve the balance of power between employees, employees perceived leadership knowledge hiding do not feel support and respect from the organization, on the one hand, don't think you can do with the leaders of the sincere communication, on the other hand lead to employees because of their own knowledge level is not high, and put forward suggestions for improvement is risky, both exchange relationship quality will reduce, LMX will reduced, reciprocal difficult to achieve, it is easier to be obedient to the leader and less likely to conduct voice behavior.

Conversely, when the knowledge distance between staff and leadership is low, employee perceived leadership knowledge distance is even higher than that of its leadership, staff and leadership power differences tend to balance, is more likely to be led into "insiders", to be able to have more opportunities to communicate with leaders and get leadership guidance. When leaders knowledge hiding to employees, employees know that the cost of acquiring knowledge from leaders is relatively low. At the same time, based on the respect and trust of leaders emotionally and professionally, employees are more inclined to give voice to leaders to improve organizational performance. In sum, we propose that:

$\mathrm{H} 3 \mathrm{a}$ : Knowledge distance moderates the relationship between perceived leader evasive hiding and LMX. The higher the knowledge distance, the more negative the relationship.

$\mathrm{H} 3 \mathrm{~b}$ : Knowledge distance moderates the relationship between perceived leader playing dumb and LMX. The higher the knowledge distance, the more negative the relationship.

H3c: Knowledge distance moderates the relationship between perceived leader rationalized hiding and LMX. The higher the knowledge distance, the less 
positive the relationship.

Figure 1 summarized all our hypotheses in a theoretical model.

\section{Methodology}

\subsection{Sample and Procedure}

Combined with the research paradigm of this paper and the limitation of objective conditions, this paper adopts the questionnaire survey method in field research to collect data. To make more broadly representative questionnaire results, this study in different parts of China multiple enterprise employees as samples, through online answer way, issuing questionnaires to employees from different provinces, finally to recycle the 483 questionnaires, eliminate invalid questionnaire, get 441 effective questionnaires, effective recovery rate reached $91.30 \%$. In the sample, males accounted for $49.66 \%$, and the gender composition was relatively balanced. From the results of age composition, 372 employees aged 35 and below were mainly involved in the study, accounting for $84.35 \%$ of the total employees, and young employees accounted for the majority.

\subsection{Measures}

In order to ensure the quality of data collection, the questionnaire design was conducted in strict accordance with the relevant guiding principles, select the mature scale with high recognition which has been used repeatedly by most scholars in existing studies.

Perceived leader knowledge hiding: Use the compiled by the scale of Connelly et al. (2012) measure in view of the subjects perceive (Arain, Bhatti, Ashraf, \& Fang, 2018), the scale is mainly divided into three dimensions (evasive hiding, playing dumb, rationalized hiding), each dimension 4 item, a total of 12 item, scale adopted at six Likert scale. The alpha reliability value for this scale is 0.88 .

Knowledge distance: Using the scale compiled by Cummings and Teng (2003) and based on the research of Jiangang and Lingna (2014), four items of the knowledge distance scale were obtained according to the Chinese context, including 1 forward question and 3 reverse questions. The alpha reliability value for this scale is 0.81 .

LMX: The seven-item scale used by Janssen and Van Yperen (2004) was

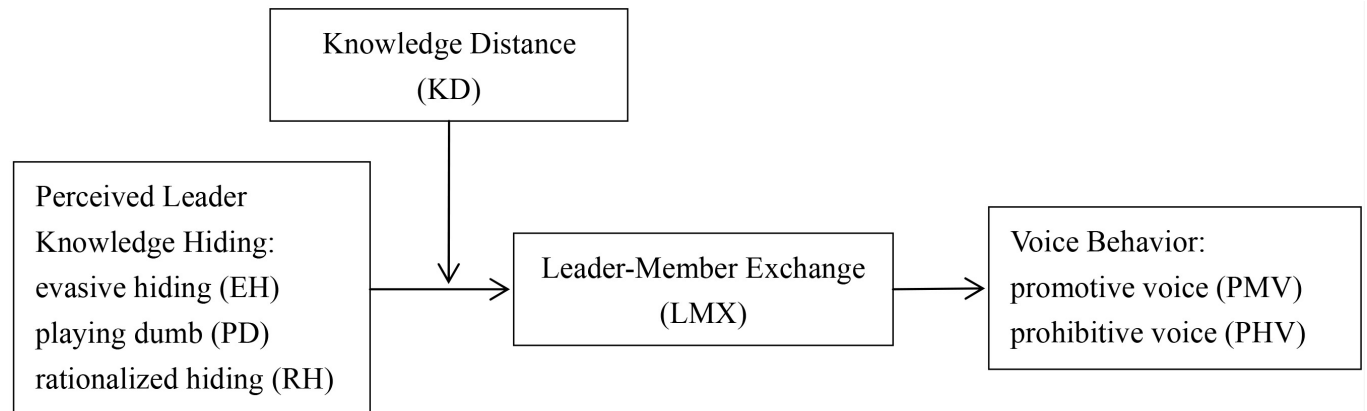

Figure 1. Theoretical model. 
adopted to measure LMX by domestic scholars. The alpha reliability value for this scale is 0.84 .

Voice behavior: The promotive voice ( 5 items) and prohibitive voice (5 items) scales developed by Liang et al. (2012) were adopted. In addition, according to previous studies, the two different voice behavior have great differences, so this study also discusses the differences. The alpha reliability value for this scale is 0.89 .

\subsection{Results}

Validity test: A confirmatory factor analysis (CFA) was conducted using LISREL 8.0 to test for the distinctiveness and validity of scales. The 1-factor, 2-factor, 3-factor, 4-factor, 5-factor, 6-factor and 7-factor models were respectively constructed and compared. It can be seen from Table 1 that factor 7 is the best fitting model, indicating that the variables studied have a high discriminant validity.

Correlation analysis: Descriptive statistics including means, standard deviations, reliability coefficients, and correlations among all study variables were computed. All the study variables possess a satisfactory level of internal consistency reliability. The coefficients of correlation among control variables, independent variables, regulatory variables, intermediary variables and dependent variables involved in this study are shown in Table 2. It can be seen from the data in the table that most of the seven major variables are pairwise significantly correlated $(p<0.01)$, and all of them show medium and low correlation levels, indicating that subsequent empirical studies are unlikely to be affected by collinearity. However, the correlation coefficient between perceived leader rationalized

Table 1. Comparison of model structure.

\begin{tabular}{|c|c|c|c|c|c|c|c|c|c|c|}
\hline Model & Factors & $x^{2}$ & $d f$ & $\chi^{2} / d f$ & $\Delta \chi^{2}(\Delta d f)$ & $R M S E A$ & $N F I$ & $C F I$ & $I F I$ & $G F I$ \\
\hline Basic Model & $\begin{array}{c}\text { 7-factor: EH, PD, RH, KD, LMX, } \\
\text { PMV, PHV }\end{array}$ & 1016.50 & 474 & 2.14 & - & 0.05 & 0.94 & 0.97 & 0.97 & 0.88 \\
\hline Model 1 & $\begin{array}{c}\text { 6-factor: } \mathrm{EH}+\mathrm{PD}, \mathrm{RH}, \mathrm{KD}, \mathrm{LMX} \\
\text { PMV, PHV }\end{array}$ & 1068.57 & 480 & 2.23 & $52.07^{\star * *}(6)$ & 0.05 & 0.94 & 0.97 & 0.97 & 0.87 \\
\hline Model 2 & $\begin{array}{l}\text { 5-factor: } \mathrm{EH}+\mathrm{PD}+\mathrm{RH}, \mathrm{KD} \\
\text { LMX, PMV, PHV }\end{array}$ & 1124.27 & 485 & 2.32 & $107.77^{\star * \star}(11)$ & 0.06 & 0.94 & 0.97 & 0.97 & 0.87 \\
\hline Model 3 & $\begin{array}{c}\text { 4-factor: } \mathrm{EH}+\mathrm{PD}+\mathrm{RH}, \mathrm{KD} \\
\mathrm{LMX}, \mathrm{PMV}+\mathrm{PHV}\end{array}$ & 1260.29 & 489 & 2.58 & $243.79^{\star \star \star}(15)$ & 0.06 & 0.93 & 0.96 & 0.96 & 0.85 \\
\hline Model 4 & $\begin{array}{c}\text { 3-factor: } \mathrm{EH}+\mathrm{PD}+\mathrm{RH}, \mathrm{KD}, \mathrm{LMX} \\
+\mathrm{PMV}+\mathrm{PHV}\end{array}$ & 2156.53 & 492 & 4.38 & $1140.03^{* * *}(18)$ & 0.09 & 0.91 & 0.93 & 0.93 & 0.77 \\
\hline Model 5 & $\begin{array}{c}\text { 2-factor: } \mathrm{EH}+\mathrm{PD}+\mathrm{RH}, \mathrm{KD}+ \\
\mathrm{LMX}+\mathrm{PMV}+\mathrm{PHV}\end{array}$ & 2785.79 & 494 & 5.64 & $1769.29^{* * *}(20)$ & 0.10 & 0.88 & 0.91 & 0.91 & 0.72 \\
\hline Model 6 & $\begin{aligned} & \text { 1-factor: } \mathrm{EH}+\mathrm{PD}+\mathrm{RH} \\
+ & \mathrm{KD}+\mathrm{LMX}+\mathrm{PMV}+\mathrm{PHV}\end{aligned}$ & 7160.20 & 495 & 14.47 & $6143.70^{* * *}(21)$ & 0.18 & 0.80 & 0.82 & 0.82 & 0.50 \\
\hline
\end{tabular}

Note: $\mathrm{N}=441 . \mathrm{EH}=$ perceived leader evasive hiding; $\mathrm{PD}=$ perceived leader playing dumb; $\mathrm{RH}=$ perceived leader rationalized hiding; $\mathrm{KD}=\mathrm{knowledge}$ distance; $\mathrm{LMX}=$ leader-member exchange; $\mathrm{PMV}=$ promotive voice; $\mathrm{PHV}=$ prohibitive voice. ${ }^{*} p<0.05,{ }^{* *} p<0.01,{ }^{* * *} p<0.001$. 
Table 2. Descriptive statistics and intercorrelations.

\begin{tabular}{|c|c|c|c|c|c|c|c|c|c|c|c|c|c|}
\hline Variable & M & $\mathrm{SD}$ & 1 & 2 & 3 & 4 & 5 & 6 & 7 & 8 & 9 & 10 & 11 \\
\hline 1. Gender & 1.50 & 0.50 & - & & & & & & & & & & \\
\hline 2. Age & 1.90 & 0.66 & $-0.13^{\star \star}$ & - & & & & & & & & & \\
\hline 3. Education & 1.86 & 0.53 & -0.02 & $0.26^{* * *}$ & - & & & & & & & & \\
\hline 4. Tenure & 2.07 & 0.97 & $-0.13^{\star \star}$ & $0.70^{* * *}$ & $0.29^{\star * *}$ & - & & & & & & & \\
\hline 5. $\mathrm{EH}$ & 3.27 & 0.99 & -0.01 & $-0.10^{*}$ & -0.03 & $-0.15^{\star *}$ & $(0.74)$ & & & & & & \\
\hline 6. PD & 2.77 & 1.02 & $-0.12^{*}$ & -0.01 & 0.03 & -0.07 & $0.70^{* * *}$ & $(0.79)$ & & & & & \\
\hline 7. $\mathrm{RH}$ & 2.95 & 1.04 & $-0.11^{\star}$ & -0.03 & 0.05 & -0.06 & $0.54^{* * *}$ & $0.69^{* * *}$ & $(0.73)$ & & & & \\
\hline 8. KD & 3.00 & 0.87 & 0.04 & $-0.26^{\star * *}$ & $-0.13^{\star *}$ & $-0.32^{* * *}$ & $0.11^{*}$ & $0.17^{* * *}$ & 0.04 & $(0.81)$ & & & \\
\hline 9. LMX & 4.43 & 0.76 & -0.05 & $0.18^{* * *}$ & $0.11^{*}$ & $0.27^{* * *}$ & $-0.31^{\star * *}$ & $-0.34^{* * *}$ & $-0.19^{\star * *}$ & $-0.54^{* * *}$ & $(0.84)$ & & \\
\hline 10. PMV & 4.50 & 0.87 & $-0.20^{\star * *}$ & $0.18^{* * *}$ & $0.19^{* * *}$ & $0.29^{* * *}$ & $-0.17^{\star \star *}$ & $-0.16^{* *}$ & -0.06 & $-0.35^{* * *}$ & $0.55^{\star * *}$ & $(0.86)$ & \\
\hline 11. PHV & 4.06 & 0.89 & $-0.15^{\star *}$ & $0.14^{* *}$ & 0.05 & $0.25^{\star * \star}$ & $-0.11^{\star}$ & $-0.10^{\star}$ & 0.02 & $-0.30^{\star \star \star}$ & $0.48^{\star * *}$ & $0.66^{* * *}$ & $(00.81)$ \\
\hline
\end{tabular}

Note: $\mathrm{N}=441$. Gender: 1 = male, $2=$ female; Age: $1=25$ and under, $2=26-35,3=36-50,4=$ more than 50; Education: $1=$ junior college and below, $2=$ bachelor, $3=$ postgraduate or above; Tenure: $1=2$ and under, $2=3-5,3=6-10,4=$ more than $10 ;{ }^{*} p<0.05,{ }^{* *} p<0.01,{ }^{* * *} p<0.001$; The Numbers in brackets are the internal consistency coefficients of each scale.

hiding in independent variable and promotive voice in dependent variable is $-0.06(p>0.05)$, while the correlation coefficient between perceived leader rationalized hiding and prohibitive voice is $0.02(p>0.05)$, which has no significant correlation. Therefore, the H1c May not be valid, which needs to be verified later. It can be seen from the table of relative numbers that there are obvious distinctions between perceived leader evasive hiding, playing dumb and rationalized hiding, which indicates the necessity of separate discussion in this paper.

\subsubsection{The Relationship between Perceived Leadership Knowledge Hiding, LMX and Voice Behavior \\ 1) Perceived leadership evasive hiding, LMX and voice behavior}

According to the classical method of testing the mediation variables proposed by Baron and Kenny (1986), Table 3 shows the results of hierarchical regression analysis when evasive hiding as independent variables. According to M2, perceived leadership evasive hiding has a significant negative influence on promotive voice $(\beta=-0.13, p<0.01)$. Similarly, M5 takes prohibitive voice as the dependent variable and perceived leadership evasive hiding as the independent variable to construct the regression equation, whose $\mathrm{F}$ value reaches the significant level. The regression results showed that perceived leadership evasive hiding had a significant negative effect on prohibitive voice $(\beta=-0.08, p<0.01)$, which supported H1a.

As shown in M8 in Table 3, perceived leadership evasive hiding has a significant negative impact on LMX $(\beta=-0.27, p<0.001)$. According to the regression results in Table $3 \mathrm{M} 3$, LMX has a significant positive effect on promotive voice ( $\beta=0.50, p<0.001$ ), but the negative effect of perceived leadership evasive hiding on promotive voice is not significant $(\beta=-0.01, p>0.05)$. Therefore, LMX 
Table 3. Hierarchical regression analysis (evasive hiding as independent variable).

\begin{tabular}{|c|c|c|c|c|c|c|c|c|}
\hline \multirow{2}{*}{ Variable } & \multicolumn{3}{|c|}{ PMV } & \multicolumn{2}{|c|}{ PHV } & \multicolumn{3}{|c|}{ LMX } \\
\hline & M1 & M2 & M3 & M4 & M5 & M6 & M7 & M8 \\
\hline \multicolumn{9}{|l|}{ Control } \\
\hline Gender & $-0.16^{\star * *}$ & $-0.16^{\star * *}$ & $-0.16^{\star * *}$ & $-0.12^{\star}$ & $-0.12^{\star}$ & $-0.11^{\star \star}$ & 0.00 & -0.01 \\
\hline Age & -0.08 & -0.08 & -0.06 & -0.07 & -0.07 & -0.06 & -0.04 & -0.04 \\
\hline Education & $0.10^{*}$ & $0.11^{\star}$ & $0.10^{*}$ & -0.04 & -0.03 & -0.04 & 0.01 & 0.02 \\
\hline Tenure & $0.23^{\star * \star}$ & $0.22^{\star \star}$ & 0.11 & $0.29^{\star * \star}$ & $0.28^{\star * *}$ & $0.18^{\star \star}$ & $0.26^{\star * *}$ & $0.22^{\star *}$ \\
\hline \multicolumn{9}{|l|}{ Independent } \\
\hline $\mathrm{EH}$ & & $-0.13^{* *}$ & 0.01 & & $-0.08^{\star \star}$ & 0.05 & & $-0.27^{\star * *}$ \\
\hline \multicolumn{9}{|l|}{ Mediating } \\
\hline LMX & & & $0.50^{\star \star \star}$ & & & $0.46^{\star * *}$ & & \\
\hline$R^{2}$ & 0.14 & 0.16 & 0.37 & 0.09 & 0.10 & 0.27 & 0.09 & 0.16 \\
\hline$\Delta R^{2}$ & 0.14 & 0.02 & 0.23 & 0.09 & 0.01 & 0.18 & 0.09 & 0.07 \\
\hline$F$ & $10.25^{\star * *}$ & $10.16^{* * *}$ & $27.96^{\star * *}$ & $6.06^{* * *}$ & $5.68^{\star * *}$ & $17.64^{* * *}$ & $6.00^{* * *}$ & $10.29^{* * *}$ \\
\hline
\end{tabular}

Note ${ }^{\star} p<0.05,{ }^{* *} p<0.01,{ }^{* * *} p<0.001$.

completely mediates the negative relationship between perceived leadership evasive hiding and promotive voice. Similarly, when prohibitive voice as dependent variable, according to M6, LMX completely mediates the negative relationship between perceived leadership evasive hiding and prohibitive voice, support the H2a.

\section{2) Perceived leadership playing dumb, LMX and voice behavior}

In the same way, according to the Table 4, M2 perceived leadership playing dumb has a significant negative impact on promotive voice $(\beta=-0.16, p<$ 0.001 ), and M5 perceived leadership playing dumb has a significant negative impact on prohibitive voice $(\beta=-0.10, p<0.05)$, which supports H1b.

According to the regression results in Table 4 of M3 and M6, LMX completely mediates the negative relationship between perceived leadership playing dumb, promotive voice and prohibitive voice, supporting $\mathrm{H} 2 \mathrm{~b}$.

\section{3) Perceived leader rationalized hiding, LMX and voice behavior}

Table 5 shows the results of hierarchical regression analysis when rationalized hiding as independent variables. According to M2, perceived leadership rationalized hiding has no significant effect on promotive voice $(\beta=-0.07, p>0.05)$, M5 shows that perceived leadership rationalized hiding has no significant effect on prohibitive voice $(\beta=0.03, p>0.05)$, and H1c is not supported.

According to Table $5 \mathrm{M} 3$ of regression results, LMX has a significant positive effect on promotive voice $(\beta=0.50, p<0.001)$, but the effect of perceived leadership rationalized hiding on promotive voice is not significant $(\beta=0.02, p>$ 0.05). According to M6, LMX has a significant positive effect on prohibitive voice $(\beta=0.46, p<0.001)$, and perceived leadership rationalized hiding has no 
Table 4. Hierarchical regression analysis (playing dumb as independent variable).

\begin{tabular}{ccccccccc}
\hline \multirow{2}{*}{ Variable } & \multicolumn{3}{c}{ PMV } & \multicolumn{7}{c}{ PHV } & \multicolumn{3}{c}{ LMX } \\
\cline { 2 - 9 } & M1 & M2 & M3 & M4 & M5 & M6 & M7 & M8 \\
\hline Control & & & & & & & & \\
Gender & $-0.16^{* * *}$ & $-0.18^{* * *}$ & $-0.16^{* * *}$ & $-0.12^{*}$ & $-0.13^{* *}$ & $-0.11^{*}$ & 0.00 & -0.05 \\
Age & -0.08 & -0.07 & -0.06 & -0.07 & -0.07 & -0.06 & -0.04 & -0.02 \\
Education & $0.10^{*}$ & $0.12^{*}$ & $0.10^{*}$ & -0.04 & -0.03 & -0.04 & 0.01 & 0.03 \\
Tenure & $0.23^{* * *}$ & $0.22^{* *}$ & 0.11 & $0.29^{* * *}$ & $0.28^{* * *}$ & $0.18^{* *}$ & $0.26^{* * *}$ & $0.22^{* *}$ \\
Independent & & & & & & & & \\
PD & & $-0.16^{* * *}$ & 0.01 & & $-0.10^{*}$ & 0.05 & & $-0.32^{* * *}$ \\
Mediating & & & & & & & & \\
LMX & & & $0.50^{* * *}$ & & & $0.46^{* * *}$ & & \\
$R^{2}$ & 0.14 & 0.17 & 0.37 & 0.09 & 0.10 & 0.26 & 0.09 & 0.19 \\
$\Delta R^{2}$ & 0.14 & 0.03 & 0.20 & 0.09 & 0.01 & 0.17 & 0.09 & 0.10 \\
$F$ & $10.25^{* * *}$ & $10.81^{* * *}$ & $27.96^{* * *}$ & $6.06^{* * *}$ & $5.90^{* * *}$ & $17.67^{* * *}$ & $6.00^{* * *}$ & $12.60^{* * *}$ \\
\hline
\end{tabular}

Note: ${ }^{*} p<0.05,{ }^{* *} p<0.01,{ }^{* * *} p<0.001$.

Table 5. Hierarchical regression analysis (rationalized hiding as independent variable).

\begin{tabular}{ccccccccc}
\hline \multirow{2}{*}{ Variable } & \multicolumn{3}{c}{ PMV } & \multicolumn{7}{c}{ PHV } & \multicolumn{3}{c}{ LMX } \\
\cline { 2 - 8 } & M1 & M2 & M3 & M4 & M5 & M6 & M7 & M8 \\
\hline Control & & & & & & & & \\
Gender & $-0.16^{* * *}$ & $-0.17^{* * *}$ & $-0.16^{* * *}$ & $-0.12^{*}$ & $-0.11^{*}$ & $-0.10^{*}$ & 0.00 & -0.02 \\
Age & -0.08 & -0.08 & -0.06 & -0.07 & -0.07 & -0.06 & -0.04 & -0.04 \\
Education & $0.10^{*}$ & $0.11^{*}$ & $0.10^{*}$ & -0.04 & -0.04 & -0.05 & 0.01 & 0.02 \\
Tenure & $0.23^{* * *}$ & $0.23^{* *}$ & 0.11 & $0.29^{* * *}$ & $0.30^{* * *}$ & $0.18^{* *}$ & $0.26^{* * *}$ & $0.24^{* * *}$ \\
Independent & & & & & & & & \\
RH & & -0.07 & 0.02 & & 0.03 & $0.11^{* *}$ & & $-0.17^{* * *}$ \\
Mediating & & & & & & & & \\
LMX & & & $0.50^{* * *}$ & & & $0.46^{* * *}$ & & \\
$R^{2}$ & 0.14 & 0.15 & 0.37 & 0.09 & 0.09 & 0.28 & 0.09 & 0.12 \\
$\Delta R^{2}$ & 0.14 & 0.01 & 0.22 & 0.09 & 0.00 & 0.19 & 0.09 & 0.03 \\
$F$ & $10.25^{* * *}$ & $9.28^{* * *}$ & $28.00^{* * *}$ & $6.06^{* * *}$ & $5.35^{* * *}$ & $18.52^{* * *}$ & $6.00^{* * *}$ & $7.21^{* * *}$ \\
\hline
\end{tabular}

Note: ${ }^{\star} p<0.05,{ }^{* *} p<0.01,{ }^{* * *} p<0.001$.

significant effect on prohibitive voice $(\beta=0.11, p<0.01)$. Therefore, $\mathrm{H} 2 \mathrm{c}$ is not supported.

\subsubsection{Study on the Moderating Effect of Knowledge Distance}

In order to test the moderating effect of knowledge distance, this study adopts hierarchical regression method to standardize data, construct product terms, and 
then carry out two-step regression. The analysis results are shown in Table 6.

$\mathrm{KD}$ on $\mathrm{EH} \rightarrow$ LMX: It can be seen from M2 in Table 6 that perceived leadership evasive hiding has a significant effect on $\operatorname{LMX}(\beta=-0.26, p<0.001)$. After the product of evasive hiding and knowledge distance is constructed, the interaction is significant $(\beta=-0.18, p<0.001)$, indicating that knowledge distance has a significant regulating effect on the relationship between perceived leadership evasive hiding and LMX. In order to facilitate the observation of the regulating effect, this paper added or subtracted one standard deviation from the mean value of the regulating variable, divided the samples into high knowledge distance and low knowledge distance to calculate the regression equation, and obtained the schematic diagram of the regulating effect. As can be seen from Figure 2, when the knowledge distance is low, the decline of LMX slows down with the increase of perceived leadership evasive hiding ( $\mathrm{B}=-0.07, p>0.05)$. When the knowledge distance is high, LMX decreases significantly with the increase of perceived leadership evasive hiding $(\mathrm{B}=-0.32, p<0.001)$, that is, with the increase of knowledge distance, perceived leadership evasive hiding has an increased negative impact on LMX. So, H3a is supported.

$\mathrm{KD}$ on PD $\rightarrow$ LMX: M3 in Table 6 shows that perceived leadership playing dumb has a significant effect on $\operatorname{LMX}(\beta=-0.26, p<0.001)$, the interaction is

Table 6. Hierarchical regression analysis of knowledge distance moderation effect.

\begin{tabular}{|c|c|c|c|c|}
\hline \multirow{2}{*}{ Variable } & \multicolumn{4}{|c|}{ LMX } \\
\hline & M1 & M2 & M3 & M4 \\
\hline \multicolumn{5}{|l|}{ Control } \\
\hline Gender & 0.00 & -0.03 & -0.05 & -0.03 \\
\hline Age & -0.04 & -0.05 & -0.05 & -0.07 \\
\hline Education & 0.01 & -0.01 & 0.00 & 0.00 \\
\hline Tenure & $0.26^{\star \star *}$ & 0.09 & 0.11 & $0.12^{*}$ \\
\hline \multicolumn{5}{|c|}{ Independent } \\
\hline $\mathrm{EH}$ & & $-0.26^{\star * *}$ & & \\
\hline PD & & & $-0.26^{\star * *}$ & \\
\hline $\mathrm{RH}$ & & & & $-0.17^{\star * *}$ \\
\hline \multicolumn{5}{|l|}{ Moderator } \\
\hline $\mathrm{KD}$ & & $-0.51^{\star * *}$ & $-0.47^{\star \star \star}$ & $-0.51^{\star * \star}$ \\
\hline \multicolumn{5}{|c|}{ Interaction term } \\
\hline $\mathrm{EH} \times \mathrm{KD}$ & & $-0.18^{\star \star *}$ & & \\
\hline $\mathrm{PD} \times \mathrm{KD}$ & & & $-0.09^{*}$ & \\
\hline $\mathrm{RH} \times \mathrm{KD}$ & & & & $-0.10^{\star}$ \\
\hline$R^{2}$ & 00.09 & 0.40 & 0.38 & 0.35 \\
\hline$\Delta R^{2}$ & 00.09 & 0.31 & 0.29 & 0.26 \\
\hline$F$ & $6.00^{* * *}$ & $29.00^{* * *}$ & $26.53^{* * *}$ & $23.19^{\star * *}$ \\
\hline
\end{tabular}




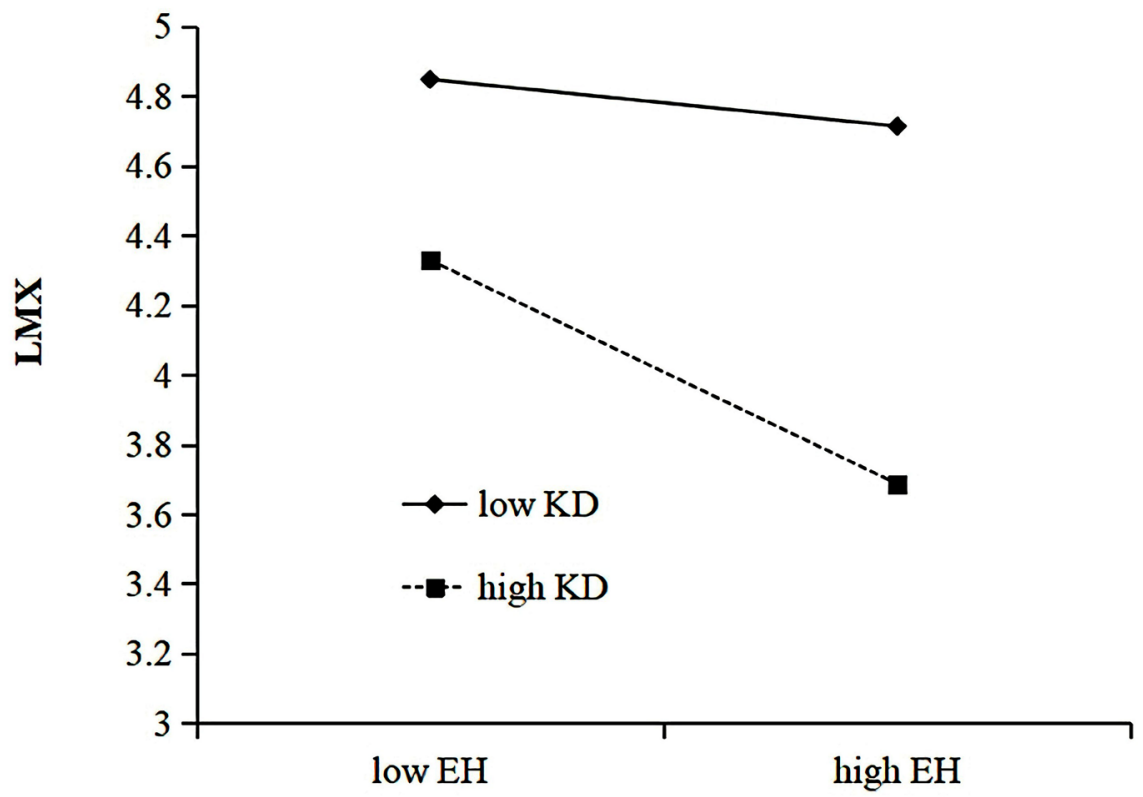

Figure 2. The moderating effect of KD on the relationship between EH and LMX.

significant $(\beta=-0.09, p<0.05)$, indicating that knowledge distance has a significant regulating effect on the relationship between perceived leadership playing dumb and LMX. As can be seen from Figure 3, when the knowledge distance is low, LMX decreases gently with the increase of perceived leadership playing dumb ( $\mathrm{B}=-0.13, p<0.01)$. When the knowledge distance is high, LMX decreases significantly with the increase of perceived leadership playing dumb $(B=$ $-0.25, p<0.001)$. In other words, with the improvement of knowledge distance, perceived leadership playing dumb increases its negative influence on LMX. So, H3b is supported.

KD on RH $\rightarrow$ LMX: It can be seen from M4 in Table 6 that perceived leadership rationalized hiding has a significant effect on $\operatorname{LMX}(\beta=-0.17, p<0.001)$ and a significant interaction effect $(\beta=-0.10, p<0.05)$. According to regulation effect Figure 4, when the knowledge distance is low, LMX decreases with the increase of rationalized hiding $(\mathrm{B}=-0.06, p>0.05)$. When the knowledge distance is high, LMX decreases significantly with the increase of rationalized hiding $(\mathrm{B}=$ $-0.19, p<0.001)$, that is, with the increase of knowledge distance, the negative influence of perceived leadership rationalized hiding on LMX increases. So H3c is not supported.

\subsubsection{The Bootstrap Test}

In order to see the moderated mediator more clearly, the Bootstrapping test was conducted. Results as shown in Table 7 and Table 8, taking the independent variable as perceived leadership evasive hiding and the dependent variable as promotive voice as an example, we can see the level of knowledge distance is lower than the average one standard deviation, $95 \%$ confidence interal is $[-0.09$, $-0.01]$, when the level of knowledge distance is average, $95 \%$ confidence interal 


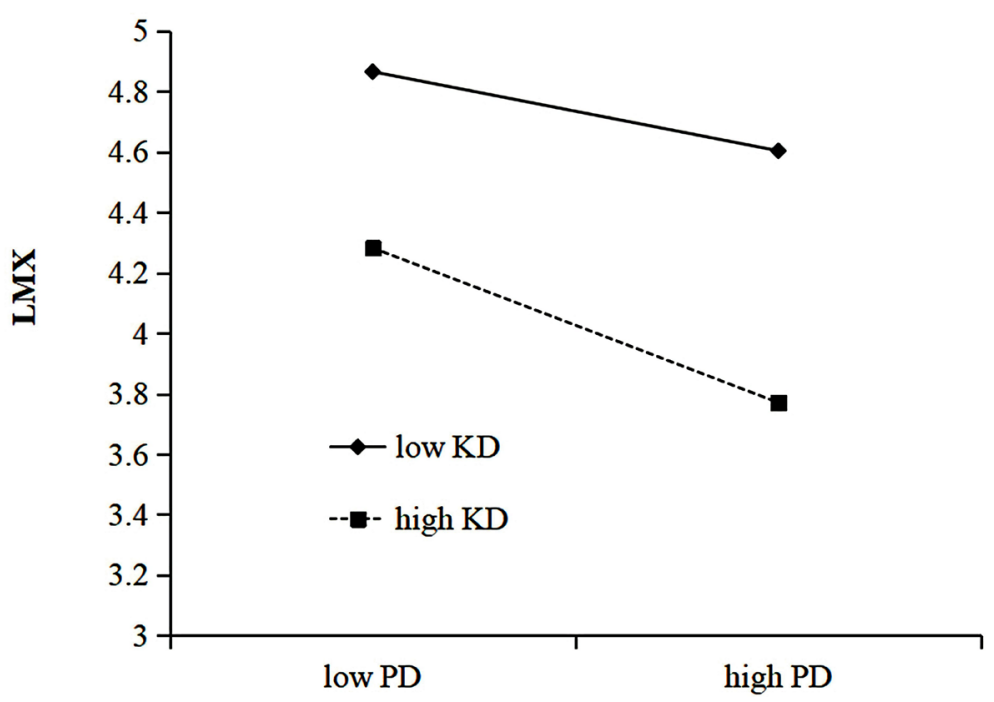

Figure 3. The moderating effect of KD on the relationship between PD and LMX.

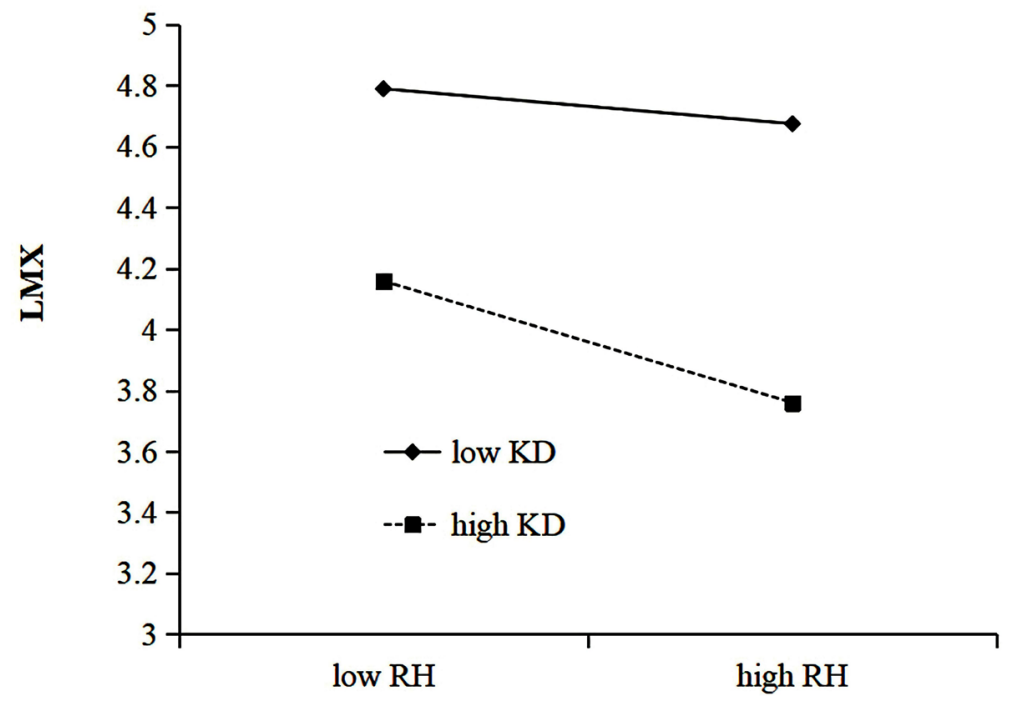

Figure 4. The moderating effect of KD on the relationship between RH and LMX.

Table 7. Indirect effects of Bootstrapping in moderating different levels (dependent variable: PMV).

\begin{tabular}{cccccc}
\hline & Different levels of KD & Effect value & SE & LLCI (95\%) & ULCI (95\%) \\
\hline \multirow{3}{*}{ EH } & -0.87 & -0.04 & 0.03 & -0.09 & -0.01 \\
& 0.00 & -0.11 & 0.02 & -0.16 & -0.07 \\
& 0.87 & -0.19 & 0.04 & -0.26 & -0.12 \\
\multirow{2}{*}{$\mathrm{PD}$} & -0.87 & -0.07 & 0.02 & -0.12 & -0.03 \\
& 0.00 & -0.11 & 0.02 & -0.16 & -0.06 \\
& 0.87 & -0.14 & 0.04 & -0.21 & -0.07 \\
\multirow{2}{*}{$\mathrm{RH}$} & -0.87 & -0.03 & 0.03 & -0.08 & 0.02 \\
& 0.00 & -0.07 & 0.02 & -0.11 & -0.03 \\
& 0.87 & -0.11 & 0.04 & -0.18 & -0.04 \\
\hline
\end{tabular}

Note: $\mathrm{N}=441$. Bootstrapping was sampled 2000 times. 
Table 8. Indirect effects of Bootstrapping in moderating different levels (dependent variable: $\mathrm{PHV}$ ).

\begin{tabular}{cccccc}
\hline & Different levels of KD & Effect value & SE & LLCI (95\%) & ULCI (95\%) \\
\hline \multirow{3}{*}{ EH } & -0.87 & -0.04 & 0.02 & -0.08 & -0.01 \\
& 0.00 & -0.10 & 0.02 & -0.15 & -0.07 \\
& 0.87 & -0.17 & 0.04 & -0.25 & -0.11 \\
& -0.87 & -0.07 & 0.02 & -0.12 & -0.03 \\
$\mathrm{PD}$ & 0.00 & -0.10 & 0.02 & -0.15 & -0.06 \\
& 0.87 & -0.13 & 0.04 & -0.21 & -0.06 \\
& -0.87 & -0.03 & 0.02 & -0.08 & 0.02 \\
$\mathrm{RH}$ & 0.00 & -0.07 & 0.02 & -0.11 & -0.03 \\
& 0.87 & -0.10 & 0.04 & -0.18 & -0.04 \\
\hline
\end{tabular}

Note: $\mathrm{N}=441$. Bootstrapping was sampled 2000 times.

is $[-0.16,-0.07]$, when the distance knowledge level on average a higher standard deviation, $95 \%$ confidence interal is $[-0.26,-0.12]$, with the improvement of knowledge distance level, confidence interval does not include 0 and became smaller. This indicates that with the improvement of knowledge distance, employees who perceive leadership evasive hiding have lower LMX, thereby reducing employee promotive voice.

\section{Discussion}

This research combines the theory of social exchange, etc., on the basis of previous research results and logical deduction, from the perspective of employee knowledge seekers, to analyze and examine the different dimensions of perceived leadership knowledge hiding influence on employees' voice behavior, the mediating role of LMX in it and the situational moderating role of knowledge distance.

Through theoretical analysis and empirical test, the regression analysis results and the Bootstrap test of the mediating effect of the survey data of $441 \mathrm{em}$ ployees showed that under the premise of controlling the background variables, perceived leader evasive hiding and playing dumb have a significant negative influence on the voice behavior of employees, while the rationalized hiding has no significant influence on the voice behavior. The evasive hiding and playing dumb of leaders are related to the deception. When employees seek knowledge from leaders, they are deliberately rejected and given deceptive explanations, which will affect the status of leaders in the minds of employees. As a result, a series of negative perceptions are generated, which reduces promotive voice and prohibitive voice of employees. However, the perceived leader rationalized hiding is due to the particularity or regulation of knowledge itself. The leaders hide knowledge from employees for the purpose of protecting employees or the company with convincing explanations. Employees can feel the original inten- 
tion of the leaders and will not blame or resent the leaders.

The negative influence of perceived leader evasive hiding and playing dumb on employees' voice behavior shows that employees' voice behavior is closely related to leaders' behavior, which reflects the view that voice behavior decision-making is based on rational analysis and the expectation of the result is positive, and expands the research on antecedents of voice behavior.

On the basis of correlation analysis, a structural equation model was built to deduce perceived leader evasive hiding and playing dumb, LMX and employee voice behavior, and a good fitting effect was obtained, proving that LMX plays a significant mediating role in the influence of perceived leader evasive hiding and playing dumb on employee voice behavior.

Knowledge hiding is the interaction behavior among the members of an organization. The quality of interaction is determined by the quality of interpersonal relationship. The establishment and maintenance of interpersonal relationship should follow certain reciprocity norms. At the same time, it puts forward the concept of negative reciprocity norm, and people should fight back and retaliate against those who cause them harm. Therefore, those who hold negative reciprocity norm often feel upset and troubled because of the betrayal or betrayal of others, thus affecting the trust relationship between each other. Therefore, employees who perceive leaders' evasive hiding and playing dumb think that they are not valued by the leaders to a certain extent, which leads to the decrease of LMX, less and less interaction between the two sides, weakened trust and commitment between each other, and less willingness to conduct voice behavior.

The empirical results of this paper are not only consistent with previous studies on the influence of LMX on voice behavior, but also find out the important influence of knowledge hiding of leaders on employee voice behavior. The confirmation of the intermediary role of LMX from the perspective of knowledge seekers clarifies the mechanism of perceived leadership knowledge hiding on voice behavior and provides guidance for promoting employee active voice behavior.

Knowledge distance plays a positive regulatory role in the relationship between three dimensions of perceived leadership knowledge hiding and LMX. In an organization, the greater the knowledge distance between employees and leaders, the lower the degree of knowledge overlap between them and the higher the barrier of professional knowledge, thus forming a larger cognitive distance. Employees with low knowledge status find it difficult to understand and absorb the knowledge shared by employees with high knowledge status. At the same time, employees with high knowledge status will also affect their initiative to share due to the asymmetric output and input of knowledge resources in the sharing activities. Based on the judgment of this situation and the need for fair social exchange, employees' initiative in knowledge communication and communication will be reduced, thus weakening the motivation for learning, making it difficult to form divergent thinking and conduct voice behavior. 
At the level of high knowledge distance, the knowledge hiding of leaders gives employees the cognition of those in low knowledge status, which is not conducive to the formation of tacit understanding LMX between employees and their superiors, and it is difficult for employees to obtain the material or spiritual support required by leaders for voice behavior activities. Moreover, for employees, voice behavior itself is full of complexity and risks of failure. A large knowledge gap with the leader will make individuals more worried about their low level of knowledge. The greater the risk of voice behavior, the harder it is to break the rules, and the easier it is to obey the orders of the superior, thus making them less likely to perform voice behavior. Employees with low knowledge distance from the leadership whether have knowledge resources are worth to own, is easy to obtain and absorb each other's perception of the knowledge more clearly and feel the leader knowledge hiding about their cause less adverse effect, employees may get by way of autonomous learning and so on to seek knowledge, knowledge of leadership have the usefulness and the availability of the evaluation of higher, impact on LMX is abate, expected learning cost and voice reduce uncertainty.

This result clarifies the different effects of the knowledge hiding of leaders on LMX under the context of different levels of knowledge distance, which further affects voice behavior, and expands the study on the situational factors that knowledge distance plays a role in from the perspective of horizontal knowledge level.

\subsection{Theoretical Implications}

From the perspective of reciprocity principle, the premise to encourage employees to actively participate in organizational voice behavior is that employees believe that the relationship between themselves and the organization is mutual trust, respect and satisfaction. As one of the obstacles to knowledge circulation in an organization, leader knowledge hiding affects individual voice behavior by affecting individual trust and interpersonal relationship, which is only in the theoretical discussion stage. Moreover, knowledge hiding and voice behavior perceived by employees are affected by their own knowledge level. Based on the literature review and logical deduction, this paper constructs the perceived leader knowledge hiding impact on employee voice behavior model, through the analysis of the large sample data validation perceived leadership evasive hiding, playing dumb and rationalized hiding the employees directly influence the promotive voice and prohibitive voice. It enriches the theoretical and empirical research on the influence and consequence of leader knowledge hiding.

Based on the importance of the guanxi between China's situation and social exchange theory of derivative theory leader-member exchange (LMX) theory, the introduction of LMX as intermediary variables, broaden the research on antecent and consequence of LMX from the perspective of knowledge seekers and provides a theoretical framework for understanding the mechanism of perceived 
leader knowledge hiding on employee voice behavior.

This paper explores the boundary function of knowledge distance. As the performance of knowledge potential difference between individuals, knowledge distance plays an important role in the knowledge flow between employees and employees, leaders and employees, and deepens the understanding that leadership knowledge hiding has different functions in different situations.

\subsection{Practical Implications}

In this paper, the perception of perceived leader knowledge hiding and employees voice behavior of the response to the current enterprise focus on knowledge management and the employees of the hot topics, to explore the influence factors of enterprise organization leadership knowledge hiding behavior, for enterprises under the background of knowledge economy era of human resource management to provide some enlightenment.

From the perspective of social exchange, this paper points out the possible factors affecting employees' voice behavior between leaders and employees within an organization, knowledge hiding of leaders and LMX. This paper discusses the influence of different types of knowledge hiding of perceived leadership on employees' promotive voice and prohibitive voice, and puts forward suggestions for employees' active knowledge sharing, leadership and subordinate communication. In the face of employee knowledge seeking, leaders reduce evasive hiding and playing dumb, as far as possible rationalized hiding. Evasive hiding and playing dumb are more likely to harm the relationship than rationalized hiding, because they are obviously intended to hide without providing the knowledge requested by the requester. Furthermore, in the process of communication and interaction between leaders and employees, they should pay attention to the communication methods in daily work and reduce cheating behaviors. Leaders need to tailor their staff to their needs. For managers, faced with different levels of knowledge of subordinates, managers can selectively in the communication to show itself to the subordinate appropriate levels of knowledge, according to their aptitude, to avoid potential knowledge too much lower subordinate form knowledge distance perception, so as to achieve more efficient communication between subordinates and communication, make employees more easily obtained from the superior knowledge resources and the support you need.

This paper deeply explores the influence mechanism of perceived leader knowledge hiding on voice behavior. Leaders can effectively improve the communication state between themselves and employees, reduce concealment and deception, establish the exchange of leaders and members who trust each other, and provide guidance for stimulating employees' voice behavior in terms of personnel management. The organization needs to build a good exchange of leadership members. Managers should pay attention to establish a good relationship with subordinates, efforts to improve staff members exchange relation- 
ship level, LMX reflects the vertical relationship between the superior and the subordinate subordinate to the leadership of the emotional engagement, contribute to, loyalty and the professional honor level evaluation, is active in affect employee work to leadership for resources, an important factor of active learning. Therefore, on the one hand, managers should convince people with excellent professional ability and good moral character, improve employees' following ability and professional respect for leaders, so as to motivate employees to actively seek valuable knowledge from leaders. Managers also need to actively communicate with subordinates on the other hand, the initiative for his subordinates and employees obtain innovation of external knowledge resources needed to create the opportunity to exchange, improve employee loyalty and contribution, to reduce staff and superior too much knowledge distance perception gap, to further reduce the cost of staff recommendations to management, promote employee voice.

This paper verifies the moderating effect of knowledge distance on the influence of perceived leader knowledge hiding on employees' voice behavior, which can provide a feasible reference for enterprise managers in stimulating the management practice of employees' voice behavior with different knowledge levels in terms of talent allocation according to different knowledge bases and professional levels between employees and leaders. The organization needs to build a reasonable structure of talent ladder. The study found that under the premise of a lower knowledge distance between leaders and employees, the negative effect of leadership knowledge hiding on voice behavior would be weakened. For a department or team, the greater the knowledge distance between the leader and members, the greater the relative difference of the knowledge potential, which is not conducive to the communication and learning between the leaders and members, and affects the overall performance of the department or team. Therefore enterprise human resources department in the staff recruitment and configuration, should fully evaluate organization department managers and their team members' knowledge reserve, experience level, factors such as technical ability, for the department or team recruitment and configuration of the corresponding level of talent, forming the reasonable personnel arrangement, in order to reduce the excessive knowledge distance between the employee and the leader inhibits LMX and the employee's active voice behavior.

\subsection{Limitations and Future Research}

Based on previous studies, this paper explores the influence mechanism of perceived leader knowledge hiding on employee voice behavior from the perspective of knowledge hiding, and then adds the mediating effect of LMX and the moderating effect of knowledge distance. Future research can be done from other perspectives.

The differences between evasive hiding and playing dumb could be discussed. In this study, there was no significant difference between perceived leader eva- 
sive hiding and playing dumb, and the same results were obtained. However, the study of Connelly et al. (2003) divided knowledge hiding behavior into three categories, and there were differences between them. At present, the differences of rationalized hiding were confirmed, while the differences between evasive hiding and playing dumb were not reflected. Future studies can try to deepen from this perspective.

Explore the influence of different dimensions of knowledge hiding. Domestic scholars have developed two categories of knowledge hiding: active hiding and passive hiding. In the original definition, knowledge hiding was regarded as "deliberate", but in fact, such deliberate, may be active, for example, deliberately shifting responsibility to the leader to keep secret, so it cannot be said, or may be passive, for example, this knowledge is really important, involving confidentiality and cannot be said. Therefore, organizational knowledge hiding behavior may also include many other behaviors.

Other theoretical perspectives can be explored in the future. From the perspective of social exchange theory, this study focuses on subordinate and explores their facing leaders' knowledge hiding and their subsequent voice behavior. Employees' attribution of leadership knowledge hiding (motivational attribution theory), and the influence of leadership knowledge hiding on employees' emotion and behavior (affective event theory) can all affect employees' choice of voice behavior. Therefore, the above perspective can be used as a new exploration perspective.

In the future, we can explore the double-effect mechanism between leaders and employees. This paper analyzes leader knowledge hiding from the perspective of employees, and the future research can consider analyzing the knowledge hiding of employees from the perspective of leaders, and the role of mutual knowledge hiding between leaders and employees, etc.

\section{Conflicts of Interest}

The author declares no conflicts of interest regarding the publication of this paper.

\section{References}

Arain, G. A., Bhatti, Z. A., Ashraf, N., \& Fang, Y. H. (2018). Top-down Knowledge Hiding in Organizations: An Empirical Study of the Consequences of Supervisor Knowledge Hiding among Local and Foreign Workers in the Middle East. Journal of Business Ethics, 1-15. https://doi.org/10.1007/s10551-018-4056-2

Avolio, B. J. (2007). Promoting More Integrative Strategies for Leadership Theory-Building. American Psychologist, 62, 25-33. https://doi.org/10.1037/0003-066X.62.1.25

Avolio, B. J., Gardner, W. L., Walumbwa, F. O., Luthans, F., \& May, D. R. (2004). Unlocking the Mask: A Look at the Process by Which Authentic Leaders Impact Follower Attitudes and Behaviors. The Leadership Quarterly, 15, 801-823.

https://doi.org/10.1016/j.leaqua.2004.09.003

Baron, R. M., \& Kenny, D. A. (1986). The Moderator-Mediator Variable Distinction in 
Social Psychological Research: Conceptual, Strategic, and Statistical Considerations. Journal of Personality and Social Psychology, 51, 1173. https://doi.org/10.1037/0022-3514.51.6.1173

Becker, T. E. (1992). Foci and Bases of Commitment: Are They Distinctions Worth Making? The Academy of Management Journal, 35, 232-244.

https://doi.org/10.5465/256481

Bergendahl, M., \& Magnusson, M. (2015). Creating Ideas for Innovation: Effects of Organizational Distance on Knowledge Creation Processes. Creativity \& Innovation Management, 24, 87-101. https://doi.org/10.1111/caim.12097

Blau, P. M. (1964). Exchange and Power in Social Life. New York: Transaction Publishers.

Butt, A. S., \& Ahmad, A. B. (2019). Are There Any Antecedents of Top-Down Knowledge Hiding in Firms? Evidence from the United Arab Emirates. Journal of Knowledge Management. https://doi.org/10.1108/JKM-04-2019-0204

Černe, M., Hernaus, T., Dysvik, A., \& Škerlavaj, M. (2017). The Role of Multilevel Synergistic Interplay among Team Mastery Climate, Knowledge Hiding, and Job Characteristics in Stimulating Innovative Work Behavior. Human Resource Management Journal, 27, 281-299. https://doi.org/10.1111/1748-8583.12132

Černe, M., Nerstad, C. G. L., Dysvik, A., \& Škerlavaj, M. (2014). What Goes around Comes around: Knowledge Hiding, Perceived Motivational Climate, and Creativity. Academy of Management Journal, 57, 172-192. https://doi.org/10.5465/amj.2012.0122

Chiaburu, D. S., \& Harrison, D. A. (2008). Do Peers Make the Place? Conceptual Synthesis and Meta-Analysis of Coworker Effects on Perceptions, Attitudes, OCBs, and Performance. Journal of Applied Psychology, 93, 1082.

https://doi.org/10.1037/0021-9010.93.5.1082

Clugston, M., Howell, J. P., \& Dorfman, P. W. (2000). Does Cultural Socialization Predict Multiple Bases and Foci of Commitment? Journal of Management, 26, 5-30. https://doi.org/10.1177/014920630002600106

Connelly, C. E., \& Zweig, D. (2015). How Perpetrators and Targets Construe Knowledge Hiding in Organizations. European Journal of Work and Organizational Psychology, 24, 479-489. https://doi.org/10.1080/1359432X.2014.931325

Connelly, C. E., Zweig, D., Webster, J., \& Trougakos, J. P. (2012). Knowledge Hiding in Organizations. Journal of Organizational Behavior, 33, 64-88. https://doi.org/10.1002/job.737

Cummings, J. L., \& Teng, B. S. (2003). Transferring R\&D Knowledge: The Key Factors Affecting Knowledge Transfer Success. Journal of Engineering and Technology Management, 20, 39-68. https://doi.org/10.1016/S0923-4748(03)00004-3

Dansereau Jr., F., Graen, G., \& Haga, W. J. (1975). A Vertical Dyad Linkage Approach to Leadership within Formal Organizations: A Longitudinal Investigation of the Role Making Process. Organizational Behavior and Human Performance, 13, 46-78. https://doi.org/10.1016/0030-5073(75)90005-7

Detert, J. R., \& Burris, E. R. (2007). Leadership Behavior and Employee Voice: Is the Door Really Open? Academy of Management Journal, 50, 869-884. https://doi.org/10.5465/amj.2007.26279183

Detert, J. R., \& Edmondson, A. C. (2006). Everyday Failures in Organizational Learning: Explaining the High Threshold for Speaking up at Work. Harvard Business School: Division of Research.

Detert, J. R., \& Treviño, L. K. (2010). Speaking up to Higher-Ups: How Supervisors and Skip-Level Leaders Influence Employee Voice. Organization Science, 21, 249-270. 
https://doi.org/10.1287/orsc.1080.0405

Dienesch, R. M., \& Liden, R. C. (1986). Leader-Member Exchange Model of Leadership: A Critique and Further Development. Academy of Management Review, 11, 618-634. https://doi.org/10.5465/amr.1986.4306242

Eisenberger, R., Armeli, S., Rexwinkel, B., Lynch, P. D., \& Rhoades, L. (2001). Reciprocation of Perceived Organizational Support. Journal of Applied Psychology, 86, 42-51. https://doi.org/10.1037/0021-9010.86.1.42

Emerson, R. M. (1962). Power-Dependence Relations. American Sociological Review, 27, 31-41. https://doi.org/10.2307/2089716

Fong, C., \& Slotta, J. D. (2018). Supporting Communities of Learners in the Elementary Classroom: The Common Knowledge Learning Environment. Instructional Science, 46, 533-561. https://doi.org/10.1007/s11251-018-9463-3

Gerstner, C. R., \& Day, D. V. (1997). Meta-Analytic Review of Leader-Member Exchange Theory: Correlates and Construct Issues. Journal of Applied Psychology, 82, 827. https://doi.org/10.1037/0021-9010.82.6.827

Gouldner, A. W. (1960). The Norm of Reciprocity: A Preliminary Statement. American Sociological Review, 25, 161-178. https://doi.org/10.2307/2092623

Graen, G. B., \& Scandura, T. A. (1987). Toward a Psychology of Dyadic Organizing. Research in Organizational Behavior, 9, 175-208.

Graen, G. B., \& Uhl-Bien, M. (1995). Relationship-Based Approach to Leadership: Development of Leader-Member Exchange (LMX) Theory of Leadership over 25 Years: Applying a Multi-Level Multi-Domain Perspective. The Leadership Quarterly, 6, 219-247. https://doi.org/10.1016/1048-9843(95)90036-5

Graen, G., Dansereau Jr., F., \& Minami, T. (1972). Dysfunctional Leadership Styles. Organizational Behavior and Human Performance, 7, 216-236.

https://doi.org/10.1016/0030-5073(72)90016-5

Gregersen, H. B. (1993). Multiple Commitments at Work and Extra-Role Behavior during Three Stages of Organizational Tenure. Journal of Business Research, 26, 31-47. https://doi.org/10.1016/0148-2963(93)90041-M

Grovier, T. (1994). An Epistemology of Trust. International Journal of Moral Social Studies, $8,155-174$.

Halliday, J. (2005). Context, Judgment, and Learning. Educational Theory, 52, 429-443. https://doi.org/10.1111/j.1741-5446.2002.00429.x

Hamel, G. (1991). Competition for Competence and Inter-Partner Learning within International Strategic Alliances. Strategic Management Journal, 12, 83-103. https://doi.org/10.1002/smj.4250120908

He, Y. M., \& Jiang, R. P. (2014). The Knowledge Hiding Behavior in Organizations: A Review and Prospect. Human Resources Development of China, 13, 49-55.

Janssen, O., \& Van Yperen, N. W. (2004). Employees' Goal Orientations, the Quality of Leader-Member Exchange, and the Outcomes of Job Performance and Job Satisfaction. The Academy of Management Journal, 47, 368-384. https://doi.org/10.5465/20159587

Jiangang, S., \& Lingna, L. (2014). Empirical Study on the Incentive Model of Knowledge Sharing within Project-Oriented Organization Based on Knowledge Potential Theory. Journal of Applied Sciences, 14, 201-211. https://doi.org/10.3923/jas.2014.201.211

Kumar Jha, J., \& Varkkey, B. (2018). Are You a Cistern or a Channel? Exploring Factors Triggering Knowledge-Hiding Behavior at the Workplace: Evidence from the Indian $\mathrm{R} \& \mathrm{D}$ Professionals. Journal of Knowledge Management, 22, 824-849.

https://doi.org/10.1108/JKM-02-2017-0048 
Le Blanc, P. M., \& González-Romá, V. (2012). A Team Level Investigation of the Relationship between Leader-Member Exchange (LMX) Differentiation, and Commitment and Performance. The Leadership Quarterly, 23, 534-544.

https://doi.org/10.1016/j.leaqua.2011.12.006

Lee, D., Choi, Y., Youn, S., \& Chun, J. U. (2017). Ethical Leadership and Employee Moral Voice: The Mediating Role of Moral Efficacy and the Moderating Role of Leader-Follower Value Congruence. Journal of Business Ethics, 141, 47-57.

https://doi.org/10.1007/s10551-015-2689-y

Liang, J., Farh, C. I. C., \& Farh, J. L. (2012). Psychological Antecedents of Promotive and Prohibitive Voice: A Two-Wave Examination. Academy of Management Journal, 55, 71-92. https://doi.org/10.5465/amj.2010.0176

Liborius, P. (2014). Who Is Worthy of Being Followed? The Impact of Leaders' Character and the Moderating Role of Followers' Personality. The Journal of Psychology, 148, 347-385. https://doi.org/10.1080/00223980.2013.801335

Liden, R. C., \& Graen, G. (1980). Generalizability of the Vertical Dyad Linkage Model of Leadership. Academy of Management journal, 23, 451-465. https://doi.org/10.2307/255511

Milliken, F. J., Morrison, E. W., \& Hewlin, P. F. (2003). An Exploratory Study of Employee Silence: Issues that Employees Don't Communicate Upward and Why. Journal of Management Studies, 40, 1453-1476. https://doi.org/10.1111/1467-6486.00387

Morrison, E. W., \& Milliken, F. J. (2000). Organizational Silence: A Barrier to Change and Development in a Pluralistic World. Academy of Management Review, 25, 706-725. https://doi.org/10.5465/amr.2000.3707697

Ng, T. W., \& Feldman, D. C. (2012). Employee Voice Behavior: A Meta-Analytic Test of the Conservation of Resources Framework. Journal of Organizational Behavior, 33, 216-234. https://doi.org/10.1002/job.754

Nguyen, B., Chen, J., \& De Cremer, D. (2017). When New Product Development Fails in China: Mediating Effects of Voice Behaviour and Learning from Failure. Asia Pacific Business Review, 23, 559-575. https://doi.org/10.1080/13602381.2017.1339455

Pan, W., Zhou, Y., \& Zhang, Q. (2016). Does Darker Hide More Knowledge? The Relationship between Machiavellianism and Knowledge Hiding. International Journal of Security and Its Applications, 10, 281-292. https://doi.org/10.14257/ijsia.2016.10.11.23

Peng, H. (2013). Why and When Do People Hide Knowledge? Journal of Knowledge Management, 17, 398-415. https://doi.org/10.1108/JKM-12-2012-0380

Riege, A. (2005). Three-Dozen Knowledge-Sharing Barriers Managers Must Consider. Journal of Knowledge Management, 9, 18-35. https://doi.org/10.1108/13673270510602746

Serenko, A., \& Bontis, N. (2016). Understanding Counterproductive Knowledge Behavior: Antecedents and Consequences of Intra-Organizational Knowledge Hiding. Journal of Knowledge Management, 20, 1199-1224. https://doi.org/10.1108/JKM-05-2016-0203

Settoon, R. P., Bennett, N., \& Liden, R. C. (1996). Social Exchange in Organizations: Perceived Organizational Support, Leader-Member Exchange, and Employee Reciprocity. Journal of Applied Psychology, 81, 219. https://doi.org/10.1037/0021-9010.81.3.219

Shore, L. M., Coyle-Shapiro, J. A. M., Chen, X. P., \& Tetrick, L. E. (2009). Social Exchange in Work Settings: Content, Mixed and Process Models. Management and Organization Review, 5, 289-302. https://doi.org/10.1111/j.1740-8784.2009.00158.x

Stinglhamber, F., Bentein, K., \& Vandenberghe, C. (2002). Extension of the Three Compo- 
nent Model of Commitment to Five Foci: Development of Measures and Substantive Test. European Journal of Psychological Assessment, 18, 123. https://doi.org/10.1027//1015-5759.18.2.123

Tangirala, S., \& Ramanujam, R. (2012). Ask and You Shall Hear (But Not Always): Examining the Relationship between Manager Consultation and Employee Voice. Personnel Psychology, 65, 251-282. https://doi.org/10.1111/j.1744-6570.2012.01248.x

Van Dyne, L., Kamdar, D., \& Joireman, J. (2008). In-Role Perceptions Buffer the Negative Impact of Low LMX on Helping and Enhance the Positive Impact of High LMX on Voice. Journal of Applied Psychology, 93, 1195.

https://doi.org/10.1037/0021-9010.93.6.1195

Venkataramani, V., Zhou, L., Wang, M., Liao, H., \& Shi, J. (2016). Social Networks and Employee Voice: The Influence of Team Members' and Team Leaders' Social Network Positions on Employee Voice. Organizational Behavior and Human Decision Processes, 132, 37-48. https://doi.org/10.1016/j.obhdp.2015.12.001

Zhu, Y., \& Akhtar, S. (2019). Leader Trait Learning Goal Orientation and Employee Voice Behavior: The Mediating Role of Managerial Openness and the Moderating Role of Felt Obligation. The International Journal of Human Resource Management, 30, 2876-2900. https://doi.org/10.1080/09585192.2017.1335338 